\title{
Da velhice estigmatizada à dignidade na existência madura: novas perspectivas do envelhecer na contemporaneidade
}

From old age stigmatized to dignity mature existence: new
perspectives of ageing in contemporary times

De la vejez estigmatizada à dignidad en la existencia madura: nuevas perspectivas del envejecimiento en la contemporaneidad

\author{
Selena Mesquita de Oliveira Teixeira * \\ Universidade de Fortaleza (UNIFOR), Fortaleza, Ceará, Brasil
}

Fernanda Xavier Santiago Marinho**

Faculdade Ateneu (FATE), Fortaleza, Ceará, Brasil

Andressa Maria Correia Vasconcelos***

Faculdade Nordeste (FANOR DeVry), Fortaleza, Ceará, Brasil

J osé Clerton de Oliveira Martins****

Universidade de Fortaleza (UNIFOR), Fortaleza, Ceará, Brasil

\begin{abstract}
RESUMO
Este artigo objetiva refletir acerca dos processos de envelhecimento e as diversas perspectivas contemporâneas que os perpassam, abordando o paradoxo que transita entre uma perspectiva mais positiva e outra com viés estigmatizador do envelhecer no contexto de nossa contemporaneidade. Empregou-se o método dialético mediante um levantamento bibliográfico das produções, em língua portuguesa, acerca do envelhecimento em uma perspectiva contemporânea nas bases de dados EBSCO e Scielo entre os anos 2004 e 2014, a partir dos descritores contemporaneidade, idoso e estigma social. Dentre os principais achados do estudo, observou-se que o estigma de "ser velho" sustenta-se na ideia de que o envelhecer, em sua essência, produz sofrimentos de diversas ordens, perda da autonomia, fragilidades, debilidades físicas, isolamento, constituindo o fim das possibilidades de se manter uma vida digna. Em contrapartida, considera-se a possibilidade de envelhecer com qualidade, preservando a dignidade de viver uma velhice repleta de experiências prazerosas, com significados profundos propiciados pelo conhecimento e apropriação de si. A velhice, como um segmento da vida com suas particularidades e características inerentes, necessariamente não deve significar um tempo de sofrimentos, fragilidades e declínios, podendo também ser vivida com qualidade, sendo o idoso o protagonista da própria vida.
\end{abstract}

ก. 2 
Palavras-chave: contemporaneidade, idoso, estigma social.

\begin{abstract}
This article aims to reflect about the aging process and the various contemporary perspectives that pervade them, addressing the paradox that moves from a more positive perspective and one with stigmatizing bias of aging in contemporary times. It was used the dialectical method by a bibliographic survey of the productions, in Portuguese, about aging in a contemporary perspective on the EBSCO and Scielo databases between 2004 and 2014, from descriptors contemporary, elderly and social stigma. Among the main findings of the study, it was observed that the stigma of "being old" supports itself on the idea that the aging, in essence, produces suffering from several orders, loss of autonomy, fragilities, physical disabilities, isolation, constituting the end of the possibilities of maintaining a dignified life. On the other hand, considers the possibility of growing old with quality, consisting of conserve the dignity, live an old age filled with pleasant experiences, with deep meanings provided by the exercise of selfknowledge. Old age, as a segment of life with their features and characteristics, not necessarily must mean a time of suffering, weaknesses and declines, it can also be lived with quality, with the elderly as the protagonist of his own life.
\end{abstract}

Keywords: contemporaneity, elderly, social stigma.

\title{
RESUMEN
}

Este artículo propone una reflexión sobre los procesos de envejecimiento y las diferentes perspectivas contemporáneas, abordando la paradoja desde una perspectiva más positiva y el sesgo estigmatizador del mayor en la contemporaneidad. El método dialéctico fue empleado desde un estudio bibliográfico de las producciones, en lengua portuguesa, sobre envejecimiento en una perspectiva contemporánea desde las bases de datos EBSCO y Scielo en el periodo entre el 2004 y el 2014, desde los descriptores: contemporaneidad, estigma social y ancianos. El estigma de la "vejez" sostiene la idea de que el envejecimiento, en esencia, trae sufrimientos tales como la pérdida de la autonomía, las fragilidades, debilidades, aislamiento físico, es decir, el extremo de las posibilidades de mantener una vida digna. Por otro lado, se consideró la posibilidad de volverse mayor con calidad, preservando la dignidad de vivir una vejez llena de experiencias agradables/positivas, con profundos significados proporcionados por el conocimiento de sí mismo. Así, se entiende que la vejez, como un segmento de la vida con sus particularidades y características, no necesariamente debe ser un momento de dificultades, debilidades y caídas. En esta etapa de la vida se puede experimentar una vida con calidad, desde que el anciano sea protagonista de su propia vida.

Palabras clave: contemporaneidad, ancianos, estigma social.

\section{Introdução}

O mundo está vivendo a "Era do Envelhecimento", nos aponta a Organização das Nações Unidas (ONU), de acordo com Herédia, Corteletti e Casara (2007). Projeções elaboradas pelo Instituto Brasileiro de Geografia e Estatística (IBGE, 2009) marcam que o Brasil ocupa o sexto lugar no ranking dos países com maior número 
de idosos, e estima-se que em 2050, a população senil superará a de jovens ( 0 a 15 anos) no País.

Para além dos dados demográficos, deve-se considerar também o fato de que os sujeitos não seguem um padrão frente ao envelhecimento. Não existe "o" processo de envelhecimento, mas "os" processos, tendo em vista que se configuram como experiências subjetivas e individuais que, por sua vez, são influenciadas pela história de vida do sujeito e o contexto cultural em que o idoso está inserido (Minayo, 2006).

Esse cenário vem atraindo a atenção de diversos países e organizações para a necessidade de investimento em pesquisas destinadas a compreender o processo de envelhecer. Com o aumento da expectativa de vida, impõe-se às diversas áreas do conhecimento - refletir acerca do processo de adaptação mundial às novas idades, visando auxiliar o seu desenvolvimento, principalmente levando-se em conta as implicações desse novo contexto para cada uma delas (Herédia, Corteletti, \& Casara, 2007).

Com isso, inicia-se a construção desta seção abordando-se o contexto contemporâneo a fim de se explorar melhor o cenário em que os sujeitos em envelhecimento estão inseridos. Quando se menciona o termo contemporaneidade, faz-se referência ao período atual da história da humanidade que se caracteriza por uma cultura consumista, na qual se privilegia o imediato e passageiro, a satisfação instantânea, os resultados visíveis em curto prazo e cujo alcance não requeira esforços prolongados (Bauman, 2004).

Desse modo, o consumo na contemporaneidade é caracterizado pelo fluxo rápido, levando a prática do descarte fácil daquilo que é considerado "velho", promovendo uma dinâmica de pronta substituição por algo novo, mais moderno, atingindo não apenas os objetos, mas também as relações e as pessoas. A juventude é cultuada, o corpo e a autonomia são supervalorizados e se exige um olhar autovigilante contínuo do sujeito, demandando constantemente que se adapte às novidades (Lipovetsky, 2009).

Com base nisso, entende-se que o consumo induz o sujeito a estar sempre descartando o que já foi superado, sobretudo os idosos, que comumente não gozam da autonomia presente nos mais jovens. A individualidade, portanto, se torna forte característica da contemporaneidade, que resulta na fragilização dos vínculos sociais.

Essa fragilidade e a insegurança que permeiam as relações na atualidade são responsáveis pela emergência dos desejos antagônicos de firmar laços e, ao mesmo tempo, investir na sua liquidez (Bauman, 2004). Estabelecer redes de relacionamentos e, ao mesmo tempo, impor-lhes limites, caracteriza a dinâmica das relações contemporâneas.

Um fator importante referente ao processo de envelhecimento na contemporaneidade é a questão da supervalorização das aparências 
quando se observa a ruptura da ordem do tempo legítimo diante da valorização da juventude, ou seja, os sujeitos buscam agregar às suas vidas o que thes confere a conotação de jovialidade. Desse modo, não se compra apenas sapatos, roupas e automóveis, mas também, juventude. Esse cenário se tornou mais intenso com a acepção da fugacidade mundana, o pesar conferido ao envelhecer, a nostalgia da juventude e a noção de finitude (Lipovetsky, 2009). Para o autor, "Aparentar menos idade agora importa muito mais do que exibir uma posição social" (p. 140).

Parecer mais jovem e esconder as marcas do corpo envelhecido remontam a uma visão estigmatizada da velhice como uma fase marcada por sentidos negativos. Há um contrassenso no que se refere às representações atribuídas ao idoso na contemporaneidade, pois de um lado, percebe-se o prestígio que lhe é conferido em razão da experiência e sabedoria acumuladas ao longo dos anos vividos; em contrapartida, tem-se a visão desse sujeito associada a estranhamento, rechaço e exclusão social (Tolotti, 2005). Essa visão social do idoso como um indivíduo improdutivo e desvalorizado permanece na atualidade, embora não na mesma intensidade, dadas as mudanças em sua realidade que ocorreram nos últimos anos, levando-a para uma perspectiva mais positiva (Goldfarb, 2004).

Levando-se em consideração a problemática apresentada, este artigo objetiva refletir acerca do envelhecer e as diversas perspectivas contemporâneas que o perpassam, abordando o paradoxo que transita entre uma perspectiva mais positiva e uma com viés estigmatizador do processo de envelhecimento na contemporaneidade.

\section{Método}

O presente artigo utilizou como estratégia orientadora do processo de investigação e análise dos dados o método dialético, que se caracteriza pela demanda de revisão e reflexão crítica dos conceitos existentes objetivando a sua incorporação ou mesmo superação crítica por parte dos pesquisadores (Lima \& Mioto, 2007).

Realizou-se um levantamento bibliográfico das produções em formato de artigos científicos, em língua portuguesa, acerca do envelhecimento em uma perspectiva mais contemporânea nas bases de dados EBSCO e Scielo entre os anos 2004 e 2014. Foram utilizados os descritores: contemporaneidade, idoso e estigma social. Como principais técnicas adotadas para a investigação procederam-se leituras sucessivas dos artigos encontrados realizadas individualmente por todos os autores participantes orientadas por Salvador (1986), cujos passos descrevem-se a seguir. Inicialmente efetuou-se uma leitura de reconhecimento do material bibliográfico e 
exploratória, consistente em leituras rápidas que objetivam selecionar o material que apresente dados referentes ao tema e verificar se tais informações interessam de fato para o estudo. Posteriormente, em uma leitura seletiva, determinou-se de fato o material de interesse, relacionando-o com o objetivo da pesquisa. Como critério de seleção do material encontrado, escolheram-se artigos que abordavam a temática do envelhecimento, contemplando perspectivas estigmatizadas e/ou positivas.

Por fim, efetivou-se uma leitura crítica ou reflexiva dos textos definitivos para, em seguida, a partir de uma leitura interpretativa, obter-se uma interpretação das ideias do autor adicionada a sua relação com o propósito da pesquisa.

Dessa forma, a análise e a interpretação dos dados desembocaram na síntese integradora que abrangeu as reflexões construídas a partir do referencial teórico no intuito de produzir aproximações críticas dos objetivos apresentados como apontam Lima e Mioto (2007).

A Figura 1, na sequência, apresenta um roteiro que serviu como base para a leitura dos artigos científicos utilizados. 
Selena Mesquita de Oliveira Teixeira, Fernanda Xavier Santiago Marinho, Andressa Maria Correia Vasconcelos, José Clerton de Oliveira Martins

\begin{tabular}{|c|c|c|}
\hline $\begin{array}{l}\text { Identificação da } \\
\text { Obra }\end{array}$ & Tema central & Objetivo da obra \\
\hline $\begin{array}{l}\text { Almeida, T., \& } \\
\text { Lourenço, M. L. } \\
\text { (2009). }\end{array}$ & $\begin{array}{l}\text { Reflexóes: conceitos, } \\
\text { estereótipos e mitos } \\
\text { acerca da velhice. }\end{array}$ & $\begin{array}{l}\text { Refletir sobre alguns conceitos e } \\
\text { estereótipos que promovem os mitos } \\
\text { entre idosos e a população em geral } \\
\text { com o intuito de auxiliar a mitigá-los. }\end{array}$ \\
\hline $\begin{array}{l}\text { Alves, } \\
\text { Moreira, C. F., \&. } \\
\text { Nogueira, } \\
(2013) .\end{array}$ & $\begin{array}{|lr|}\text { Relações } & \text { sociais, } \\
\text { estereótipos } & e \\
\text { envelhecimento. } & \\
& \\
& \end{array}$ & $\begin{array}{l}\text { Compreender a evolução do processo } \\
\text { de socialização ao longo da vida; } \\
\text { analisar as conotações atribuídas ao } \\
\text { envelhecimento e o impacto dos } \\
\text { estereótipos no envelhecimento. }\end{array}$ \\
\hline $\begin{array}{l}\text { Andrews, } \quad \text { M. } \\
\text { (1999). }\end{array}$ & $\begin{array}{l}\text { The seductiveness of } \\
\text { agelessness. }\end{array}$ & $\begin{array}{l}\text { Desafiar a opinião de que a velhice } \\
\text { não é mais que uma construçăo social. }\end{array}$ \\
\hline $\begin{array}{l}\text { Ferreira, V. R. T. } \\
\text { (2005). }\end{array}$ & \begin{tabular}{llr|} 
Psicoterapia e & pós- \\
modernidade: & & \\
problemas & da \\
subjetividade e & da \\
psicologia clinica & no \\
contemporâneo. & \\
\end{tabular} & $\begin{array}{l}\text { Discutir a problemática da pós- } \\
\text { modernidade e suas relações com a } \\
\text { psicoterapia. }\end{array}$ \\
\hline 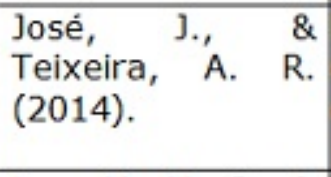 & $\begin{array}{l}\text { Envelhecimento Ativo: } \\
\text { contributo para uma } \\
\text { discussão crítica. }\end{array}$ & $\begin{array}{l}\text { Explorar e analisar as diferentes } \\
\text { concepçōes de Envelhecimento Ativo } \\
\text { veiculadas em documentos de autoria } \\
\text { de organizações supranacionais. }\end{array}$ \\
\hline $\begin{array}{l}\text { Luz, M. M. C., \& } \\
\text { Amatuzzi, M. M. } \\
\text { (2008). }\end{array}$ & $\begin{array}{l}\text { Vivências de felicidade } \\
\text { de pessoas idosas. }\end{array}$ & $\begin{array}{l}\text { Conhecer e descrever os aspectos } \\
\text { emocionais e cognitivos das vivências } \\
\text { de felicidade de pessoas idosas. }\end{array}$ \\
\hline Moreira (2012). & $\begin{array}{l}\text { Mudanças na percepção } \\
\text { sobre o processo de } \\
\text { envelhecimento: } \\
\text { reflexões preliminares. }\end{array}$ & $\begin{array}{l}\text { Realização de reflexão teórica sobre a } \\
\text { mudança na percepção do processo de } \\
\text { envelhecimento partindo de uma } \\
\text { concepção que vincula velhice a } \\
\text { declinio e prosseguindo para a } \\
\text { perspectiva do desenvolvimento } \\
\text { possivel no envelhecimento. }\end{array}$ \\
\hline $\begin{array}{l}\text { Moreira, V., \& } \\
\text { Nogueira, F. N. N. } \\
\text { (2008). }\end{array}$ & $\begin{array}{ll}\text { Do indesejável ao } \\
\text { inevitável: a experiência } \\
\text { vivida do estigma de } \\
\text { envelhecer } & \text { na } \\
\text { contemporaneidade. } & \end{array}$ & $\begin{array}{l}\text { Discutir sobre o processo de } \\
\text { envelhecimento } \\
\text { contemporaneidade ocidental a partir } \\
\text { de uma pesquisa fenomenológica } \\
\text { realizada com sujeitos colaboradores } \\
\text { na fase da maturidade. }\end{array}$ \\
\hline Neri (2004) & $\begin{array}{l}\text { Velhice bem-sucedida: } \\
\text { aspectos afetivos e } \\
\text { cognitivos. }\end{array}$ & $\begin{array}{l}\text { Resenha que objetiva descrever o livro } \\
\text { Velhice bem-sucedida: aspectos } \\
\text { afetivos e cognitivos, das autoras Neri, } \\
\text { A. L. e Yassuda, M. S. (2004). }\end{array}$ \\
\hline $\begin{array}{l}\text { Schneider, R. H., } \\
\text { \& Irigaray, T. Q. } \\
\text { (2008). }\end{array}$ & $\begin{array}{l}\text { O envelhecimento na } \\
\text { atualidade: aspectos } \\
\text { cronológicos, biológicos, } \\
\text { psicológicos e sociais. }\end{array}$ & $\begin{array}{l}\text { Indicar aspectos que configuram o } \\
\text { processo de envelhecimento na } \\
\text { sociedade atual, especificamente as } \\
\text { diferentes conceituações utilizadas } \\
\text { para defini-lo em relação aos aspectos } \\
\text { cronológicos, biológicos, psicológicos e } \\
\text { sociais envolvidos. }\end{array}$ \\
\hline $\begin{array}{l}\text { Silva, H. S., Lima, } \\
\text { A. M. M., \& } \\
\text { Galhardoni, R. } \\
(2010) .\end{array}$ & $\begin{array}{|lr|}\text { Envelhecimento rem- } \\
\text { sucedido } & \mathrm{e} \\
\text { vulnerabilidade } & \text { em } \\
\text { saúde: aproximações e } & \\
\text { perspectivas. } & \end{array}$ & $\begin{array}{l}\text { Promover uma discussão sobre o que } \\
\text { vem a ser envelhecer de forma bem- } \\
\text { sucedida, mesmo na presença de } \\
\text { vulnerabilidades. }\end{array}$ \\
\hline
\end{tabular}


FIGURA 1

Quadro de Artigos (material bibliográfico para leitura). Elaboração própria (2014).

Vale ressaltar que posteriormente, no processo de produção escrita, julgou-se necessária a utilização de uma tese de doutorado, livros de autores clássicos e conceituados que tratam dos fenômenos do envelhecimento e da contemporaneidade, assim como a consulta a documentos da Organização Mundial de Saúde (OMS).

Ao longo do processo de articulações teóricas para a construção do presente artigo, contatou-se a possibilidade de desenvolver algumas relações pertinentes com materiais de autores clássicos assim como de dados de pesquisas da Organização Mundial da Saúde a fim de enriquecer a pesquisa com informações de referência.

\section{Resultados e discussão}

Para fins didáticos, optou-se por dividir esta sessão em dois tópicos: "O estigma do Envelhecer na Contemporaneidade" e "Envelhecer com Qualidade: Perspectivas Positivas Acerca do Envelhecimento". Dessa forma, é possível identificar de forma mais clara os resultados encontrados e a discussão proposta a partir das perspectivas estigmatizadas e positivas, com base na exploração da bibliografia proposta.

\subsection{O estigma do envelhecer na contemporaneidade}

O envelhecimento da população brasileira é um fato irreversível, considerando-se a significativa diminuição das taxas de fertilidade e o aumento da longevidade evidenciado nas últimas décadas. Esse aumento representa uma relevante mudança social, que exige maior atenção para as pessoas que integram essa faixa etária (Schneider \& Irigaray, 2008).

No âmbito dessas transformações, observa-se uma quebra cultural intensa, que convoca ao desafio de substituir estereótipos e desnaturalizar a velhice como problema, reinventando normas culturais que valorizem não apenas crianças e jovens (Minayo, 2006). A velhice é período da vida historicamente construído que contempla, em sua essência, valores culturais de uma dada sociedade. Em diversos contextos sociais e tempos históricos observa-se que a velhice carrega uma marca social ligada à rejeição da figura do velho, em geral, alimentada pela ideia de improdutividade e declínio (Neri, 2006).

A própria definição do termo produz impasse, sobretudo pelos mitos que envolvem o processo de envelhecimento (Almeida \& Lourenço, 2009). Os preconceitos que perpassam o tema também colaboram 
para o não estabelecimento de uma descrição mais precisa dessa fase da vida, e podem ser aclarados com a seguinte reflexão crítica de Neri (2006, p.10):

Falsas avaliações positivas são igualmente subjacentes aos termos com que hoje os leigos designam a velhice, pensando que são melhores por não terem a mesma conotação negativa das palavras velho, idoso ou velhice. Muitas pessoas preferem expressões tais como terceira idade, boa idade, melhor idade, idade legal, maior idade, idade dourada e equivalentes. Bem analisadas, eles não passam de eufemismos, usados de forma não-crítica, para mascarar práticas baseadas em preconceitos.

Moreira e Nogueira (2008) explicam que envelhecer dentro do mundo contemporâneo significa envelhecer em um cenário de instabilidade, gerado pelas intensas transformações econômicas, sociais, políticas, ideológicas e científicas ocorridas nas últimas décadas. Tais mudanças ocorrem com muita rapidez, contribuindo para o surgimento da insegurança e a má acomodação dos sujeitos que nele vivem.

Para que haja uma melhor compreensão desse cenário, vale frisar que a contemporaneidade é marcada pelo descentramento do ser humano e pela "dissolução da natureza humana nas positividades da história e da cultura" (Domingues, 1999, p. 16). Consiste no universo de valores e normas que os indivíduos constituíram e nas relações que estabeleceram, caracterizado pela valorização desmedida de riquezas e pela eminência de questões fundamentais como individualismo, consumismo, prazer imediato e aparência (Lipovetsky, 2009).

Observa-se um esvaziamento do sujeito contemporâneo, que internaliza princípios sociais reguladores que desvalorizam o passado em prol do novo. Nessas sociedades, praticamente tudo se torna descartável e muda com muita rapidez. A regra atual é "tudo deve mudar, e mudar o mais rápido possível, pois só assim se pode manter a roda da economia" (Ferreira, 2005 p. 131).

O estigma de "ser velho" sustenta-se na ideia de que o envelhecer, em essência, produz sofrimentos de diversas ordens, perda da autonomia, fragilidades, debilidades físicas, isolamento, constituindo o fim das possibilidades de se manter uma vida digna. Observa-se uma forte associação dessas ideias ao mal-estar de não se corresponder às exigências do mundo contemporâneo, comumente experienciado pelo idoso na contemporaneidade (Moreira \& Nogueira, 2008). Tal associação encontra-se na base da rejeição à velhice, ocasionando, com frequência, o desprezo do próprio idoso quanto a sua condição (Neri \& Freire, 2000). 
Essa perspectiva negativa do envelhecer marca a sociedade contemporânea ocidental e possui como pilares de sustentação o primado estético de uma sociedade narcisista, que tem como valores a beleza do corpo, a capacidade de ser produtivo e dinâmico, a força e o novo, alimentando-se do mito da juventude inacabável. 0 inevitável envelhecer passa a ser vivido também como indesejável, em geral, por estar vinculado à ideia de finitude (Moreira \& Nogueira, 2008). Dessa maneira, a rejeição dos aspectos próprios da velhice recebe influência direta da visão que a sociedade e a cultura estabelecem sobre $o$ envelhecimento e de todo o conjunto de padrões, exigências e valores que rege o mundo contemporâneo.

No panorama de desenvolvimento humano, a velhice é desvalorizada e colocada à margem, evitada e rejeitada de diversas maneiras até pelo próprio idoso. Em contrapartida, as outras etapas da vida são contempladas e planejadas socialmente. Evidencia-se, segundo Andrews (1999), uma contradição: ao mesmo tempo em que as pessoas querem viver por longos anos, não querem experienciar a velhice e, sobretudo, parecer "velhos". Nesse sentido torna-se possível afirmar que a sociedade e a cultura têm contribuído significativamente para o florescimento do preconceito em relação a esse grupo etário.

Desse modo, na sociedade contemporânea de valores típicos, o envelhecer passa a representar uma ininterrupta luta quanto à aceitação de si mesmo, e a dimensão estética surge como aspecto fundamental para o bem-estar (Moreira \& Nogueira, 2008). A cultura midiática fortifica a valorização da beleza e do novo e, por conseguinte colabora para a desvalorização da velhice, sobretudo por meio do incentivo ao consumo e da estetização da vida.

Como resultado disso, observa-se uma forte valorização da juventude e a constituição de sociedades narcisistas e individualistas. A estetização da existência atende à demanda do espetáculo. Desse modo, convoca "um horizonte, onde os valores de profundidade e interioridade estão perdendo gradativamente espaço, sendo, em decorrência disso, substituídos por valores relativos à superfície e exterioridade" (Pitanga, 2006, p. 16).

Assim os valores negativos que contaminam o envelhecer ganham força e a velhice passa a ser desvalorizada, e em situações mais extremas, comparada a uma doença e deve ser combatida e evitada a qualquer custo. Para Debert, nesse contexto, envelhecer assume o caráter de descuido e negligência, enquanto a juventude passa a ocupar a posição de valor a ser mantido e buscado por todos (2002). Discutir sobre o processo de envelhecimento requer, principalmente, que se analise a relação desse processo com a sociedade, uma vez que o sujeito se constitui ao longo de sua vida inserido no meio social. Este atribui valor ao sujeito que produz lucro para a lógica capitalista, excluindo o idoso pelas dificuldades que frequentemente 
apresenta para corresponder às exigências impostas por essa lógica (Alves, Moreira, \& Nogueira, 2013).

Refletir acerca das crenças que envolvem a velhice no contexto contemporâneo remete à descoberta de opiniões equivocadas a esse respeito, especialmente ligadas à noção de que a velhice é um ônus para sociedade capitalista e para os que convivem com o idoso. Nesse sentido, construiu-se o retrato de que o idoso é um problema a ser solucionado, fortalecendo uma visão estereotipada da realidade (Rodrigues, 2008). Vale ressaltar que os valores e estereótipos vinculados à posição do velho em sua sociedade se distinguem de acordo com a cultura e período histórico, haja vista se tratar de uma construção social (Peres, 2007).

A resistência evidente dos membros da sociedade atual em se tornarem idosos mostra-se intimamente acoplada à supervalorização contemporânea da juventude, do belo, da autonomia, da produtividade, em que se valoriza a condição de ser reprodutivo. Aqui o envelhecer adquire uma representação negativa, equivalendo à perda de características tão estimadas socialmente, bem como pelo sujeito que envelhece (Schneider \& I rigaray, 2008).

Trata-se de uma renúncia por parte do próprio idoso ao rótulo imposto pela sociedade no que se refere a ser velho, em que se recusa a fazer parte de um grupo desvalorizado, que o lança em uma situação de desvantagem social (Moreira \& Nogueira, 2008).

O "estigma é uma opinião feita e que de forma simplista não passa de uma generalização em relação a um grupo de indivíduos ou objetos" (Alves et al., 2013, p. 4). Na sociedade brasileira é possível observar a existência de alguns mitos relacionados ao envelhecimento, que contribuem significativamente para 0 fortalecimento do estigma de ser velho. Minayo (2006) destaca os três principais mitos a respeito da velhice, consistindo o primeiro em limitar o envelhecimento apenas a uma questão orgânica, considerando o processo de envelhecer associado à decadência e interpretando a velhice como problema. Nesse caso, a velhice associada à doença e à deterioração do corpo é determinada apenas pelo critério biológico da idade cronológica, não contemplando o processo de envelhecer em sua complexidade. Na visão da autora, a vida não se reduz a apenas processos biológicos, por isso essa perspectiva é limitada, além de negar o processo em sua completude. O segundo mito mais frequente diz respeito à ideia de que o velho é descartável e se fundamenta na realidade vigente nas sociedades regidas pelo capitalismo, nas quais o sujeito vale o quanto produz para o capital. Por essa razão, o idoso, em geral, aposentado, e em outros casos, dependente financeiramente, perde o seu valor social, dando vazão a ideia de decadência associada à velhice. Nesses casos, é comum o próprio idoso, envolvido pela noção de descarte, sentir-se desvalorizado e assim buscar o isolamento do mundo (Minayo, 2006). 
Nesse sentido, Goldfarb (2006) aponta que o lugar social do velho seria quase um não lugar, pois embora a partir dos investimentos das últimas décadas sejam reconhecidos como sujeitos, incluídos no panorama cultural contemporâneo (até porque seria impossível não incluir o grupo etário que mais cresce), os velhos são empurrados para as bordas da estrutura social, reconhecidamente obrigados à subjetividade ancorada na passividade, à pobreza de trocas simbólicas e à renúncia ao papel de agentes sociais. São empurrados em direção à perda de todo poder, até sobre si mesmos.

A velhice naturalizada como problema é o terceiro mito mais comum quando se trata do envelhecimento. Essa visão negativa perpassa as relações familiares, sociais e médicas. Embora grande parte das famílias brasileiras acolha seus idosos, a maioria de seus membros ainda se queixa dos problemas de convivência intergeracionais, especialmente em casos de idosos com enfermidades crônicas. No contexto da Medicina, a população idosa é considerada vulnerável e demandante de alto custo social, por isso vista como problema (Minayo, 2006).

Em síntese, esses mitos atuam como obstáculos para a constituição de uma velhice satisfatória; contudo, o que direcionará a forma como - sujeito experimenta o próprio envelhecer são os padrões comportamentais assumidos e os aspectos psicológicos mantidos no decurso da vida. Sendo assim, a forma como o sujeito vive o seu envelhecimento é reflexo de uma construção que o mesmo fez ao longo de sua existência. A maneira como o idoso enfrenta as adversidades denota o grau de adaptação frente às crises e dificuldades comuns no envelhecimento (World Health Organization [WHO], 2005).

Vale ressaltar que o envelhecimento é um processo complexo e singular. Fatores externos podem influenciar na experiência pessoal de envelhecer, mas o envolvimento do próprio idoso é a condição essencial para que haja uma velhice satisfatória. A velhice, que para alguns pode representar o tempo da dependência e do isolamento, para outros poderá equivaler ao tempo do amadurecimento e do protagonismo (Minayo, 2006).

Sendo assim, importa compreender que a eficácia desses enfrentamentos está relacionada às experiências que o indivíduo teve durante a sua existência, incluindo os recursos internos que estruturou (WHO, 2005). Todavia, os fatores protetores que contribuem para um envelhecimento saudável mostram-se cada vez mais escassos na contemporaneidade, deixando o idoso vulnerável diante de uma velhice desprovida de sentido.

\subsection{Envelhecer com qualidade: perspectivas positivas acerca do envelhecimento}


No contexto contemporâneo, os estudos sobre o processo de envelhecimento mencionam com mais frequência os aspectos negativos que os ganhos associados a essa fase, a exemplo da sabedoria, mais habilidade e experiência nas relações interpessoais, entre outros. Tal realidade é justificada pela crença de que as perdas ocorrem somente na velhice, restringindo-se os ganhos às fases iniciais do desenvolvimento. Porém, é válido ressaltar que em todas as etapas da vida ocorrem perdas e ganhos diversificados (Luz \& Amatuzzi, 2008).

Por se tratar de uma fase caracterizada pelo declínio de funções biológicas, ainda que de forma diferenciada (Neri, 2004), associa-se muitas vezes a velhice à doença e afastamento, desconsiderando-se determinados atenuantes compensatórios do processo evolutivo.

Destacam-se, a título dessas compensações, dados de uma pesquisa brasileira sobre solidão e bem-estar na velhice que investigou as relações entre condições de vida, características das relações pessoais, sentimentos de solidão, bem como o bem-estar subjetivo em mulheres idosas que residem sós. Obteve-se que $75 \%$ delas não se consideram isoladas e atribuem seu bem-estar à capacidade de usufruir de mecanismos compensatórios como atividades laborais e sociais (Neri, 2004). Estudos como esse rejeitam estigmas como os de que os idosos são infelizes, doentes, abandonados ou incapazes de gerenciar a própria vida.

Considerando-se tais aspectos, é importante lembrar que o idoso pode reagir de diferentes maneiras ao processo de tornar-se velho, perpassado pela sua história pessoal e social, e, principalmente, guiado pelo suporte afetivo que constituiu ao longo da sua vida (Mori, 2006). Como exemplo disso, um estudo brasileiro que buscou descrever (considerando aspectos cognitivos e emocionais) como se dão as vivências de felicidade de pessoas idosas, concluiu que tais vivências estão relacionadas principalmente ao bem-estar em família, ao fato de poderem realizar atividades laborais por prazer, à espiritualidade e à manutenção de uma rede de relações sociais (Luz \& Amatuzzi, 2008).

Dados como esses levam a crer que a experiência de envelhecer assume um novo lugar na contemporaneidade, fato que se deve principalmente à inserção do idoso em atividades esportivas, envolvimento com a arte, continuidade nos estudos e trabalho, bem como participação ativa no funcionamento familiar, muitas vezes ocupando o lugar de provedor. Nessa perspectiva, emergem reflexões sobre o que vem a ser necessário para a vivência positiva da velhice, considerando-se as vulnerabilidades e perdas inerentes a esse processo.

Desde a constituição de um saber específico sobre o corpo na fase idosa, no início do século $X X$, em que se deu o nascimento da geriatria e da gerontologia, o interesse científico em relação à velhice 
permaneceu, por muitos anos, restrito à tentativa de se explicar as causas do envelhecimento e se identificar possíveis métodos para retardá-lo. Dessa maneira, até então o envelhecer constituía o irremediável destino humano, sem muitas opções de medidas terapêuticas aplicadas ao idoso (Correa, 2009).

$\mathrm{Na}$ gerontologia, a conceituação de velhice bem-sucedida foi proposta inicialmente por Havighurst somente na década de 1960, como resultado da participação do idoso em atividades associadas à satisfação, interação social e conservação da saúde. O surgimento desse conceito representou o marco de uma mudança ideológica importante nos estudos do envelhecimento, um incentivo às investigações sobre aspectos positivos ligados à velhice e sobre a capacidade de desenvolvimento nessa fase (Silva, Lima, \& Galhardoni, 2010).

Para Silva et al. (2010), o conceito de velhice bem-sucedida adquiriu uma nova conotação no fim dos anos 1980 e início dos 1990, passando a ser representado por dois modelos teóricos: o de Rowe e Kahan (1998), com base nos dados do estudo norte-americano "MacArthur Foudation Study", e o de Baltes e Baltes (1990, que sugeriu o modelo teórico de "Seleção, Otimização e Compensação (SOC)", representando as possibilidades de plasticidade funcional e comportamental no cenário das ciências psicológicas.

O primeiro modelo propõe fatores principais para um envelhecimento bem-sucedido que consistem na interação com a vida, na preservação de elevados níveis de habilidades cognitivas e funcionais e na baixa probabilidade de doenças proporcionada por comportamentos saudáveis. Já o segundo se baseia na crença de que os idosos que conseguem se servir de mecanismos de regulação e compensação das perdas vinculadas ao processo de envelhecimento conseguem alcançar a velhice bem-sucedida (Silva et al., 2010).

Paralelamente aos modelos destacados, considerando o advento do envelhecimento demográfico, a substituição progressiva na Europa do Estado Providência para os moldes de Estado Social Ativo e o surgimento do paradigma do "envelhecimento positivo", fundamentado de forma parcial por uma cultura de "antienvelhecimento", surgiu o discurso do "envelhecimento ativo" (José \& Teixeira, 2014).

A esse respeito, a Organização Mundial de Saúde (OMS) considera que "envelhecer ativamente" é também uma responsabilidade individual e acrescenta que as pessoas podem ser ativas em múltiplas áreas à medida que envelhecem. Tal concepção de "envelhecimento ativo" rejeita de forma clara a ligação de "ativo" a "fisicamente ativo" ou a "economicamente produtivo". Na perspectiva da OMS O envelhecimento ativo implica a adoção de "atividades multidimensionais", a exemplo de "atividades mentais e físicas" e/ou "atividades produtivas e não produtivas" (as práticas espirituais 
também estão incluídas no âmbito de atividades não produtivas). Vale salientar que a OMS enxerga que a participação social deveria ocorrer em concomitância com os desejos, necessidades e capacidades, de forma a excluir o imperativo de moldes que não acatem a singularidade dos indivíduos em tela (José \& Teixeira, 2014; World Health Organization, 2002).

Entende-se, portanto, que a possibilidade de envelhecer de forma boa e satisfatória é também uma questão existencial que remete à identificação de virtudes. Esse tipo de vivência positiva cresce em razão do bom funcionamento de fatores pessoais e socioculturais (Neri, 1993). A condição de experienciar a velhice como etapa natural da vida, e, sobretudo, a assimilação das transformações decorrentes do processo de envelhecimento, sem que haja renúncia ou negação a tais mudanças, ampliam as possibilidades de um envelhecer satisfatório (Silva et al., 2010).

A compreensão de que a maturidade também inclui autoconhecimento e aceitação e de que na velhice há um processo maior de investimento no autoconhecimento, gerando modos mais positivos de apreciação da vida (Sad, 2001), pode resultar em uma transformação dos estereótipos negativos acerca do envelhecimento. Silva et al. (2010) reforçam ainda que a construção de conhecimento sobre saúde, bem-estar e qualidade de vida na velhice deveria considerar que os idosos gozam de estratégias e recursos internos e externos frente aos baixos níveis de desempenho, segundo pesquisas, e que é preciso que haja uma articulação entre a vulnerabilidade social e as repercussões das condições sociais na trajetória de saúde ao longo da vida.

É preciso desmistificar a ideia de que os idosos são os únicos responsáveis pela condição de saúde que os atinge na velhice, pois essa crença pode gerar uma discriminação advinda da não adoção de hábitos de vida favoráveis no curso de suas vidas. Há, portanto, a necessidade de priorizar o oferecimento de iguais oportunidades de acesso aos serviços de saúde para o público idoso (Debert, 1999). O envelhecer bem também depende da oferta de recursos como educação, urbanização, habitação, saúde, trabalho e família (Moreira, 2012).

Nesse sentido, deve-se considerar que a problematização de temas que envolvem o cotidiano dos idosos com vulnerabilidade social pode gerar resultados que privilegiem o papel dos idosos como sujeitos de direitos. Faz-se necessário um esforço coletivo para oportunizar a todos o alcance de um envelhecimento saudável e digno (Silva et al., 2010).

Diante disso, pode-se inferir que envelhecer com qualidade é também conservar a dignidade de uma velhice repleta de experiências prazerosas, com significados profundos propiciados pelo exercício do conhecimento de si. 


\section{Considerações finais}

Neste artigo, optou-se por contextualizar e descrever diferentes perspectivas do envelhecer na contemporaneidade, elegendo como norte, sobretudo, a maneira como o idoso entende e experimenta a própria velhice, considerando as transformações intensas do mundo contemporâneo, que refletem de forma direta na estruturação do mundo interno dos sujeitos.

Em função disso, generalizações acerca da velhice costumam ser arbitrárias, à medida que a delimitação de uma noção fechada de "ser velho" impossibilita a análise de aspectos sociais, culturais e psicológicos essenciais para a compreensão desse período da vida, haja vista ser um processo singular, que assume diferentes representações conforme o contexto no qual o sujeito envelhece.

Desse modo, as diferentes formas de envelhecer perpassam categorias estruturantes como gênero, trabalho, classe social, relações familiares, sociabilidade, em suma, condições culturais, socioeconômicas e ambientais. Todavia, a maneira como cada sujeito envelhece é única, a diferenciação é baseada na subjetividade. Para Minayo (2006), "Cada pessoa retoma permanentemente os dados de sua história e os reconstrói com os fios do presente" (p. 49).

Os resultados deste estudo apontam que a velhice, como um segmento da vida com suas particularidades e características, não necessariamente deve significar um tempo de sofrimentos, fragilidades e declínios, podendo, também, ser vivida com qualidade, tendo o idoso como protagonista da própria vida. Nessa perspectiva, diversas velhices surgem, e o envelhecimento deve ser entendido como um processo único e inacabado, pois enquanto houver vida há envelhecimento.

Nesse sentido, envelhecer com qualidade surge como possibilidade mesmo em uma sociedade marcada pela cultura do repúdio à velhice, porém, para que isso aconteça, é necessário que haja também profundas transformações políticas e sociais.

A elaboração deste artigo foi motivada a partir da constatação da importância de discutir acerca do tema a fim de promover mudanças no que concerne ao lugar dado ao velho na sociedade contemporânea. Contudo, ressalta-se a necessidade de aprofundar teoricamente tais questões devido aos limites ocasionados pelo caráter subjetivo e dinâmico da temática. 


\section{Referências}

Almeida, T., \& Lourenço, M. L. (2009, maio/agosto). Reflexões: conceitos, estereótipos e mitos acerca da velhice. Revista Brasileira de Ciências do Envelhecimento Humano, 6(2), 233244.

Alves, S., Moreira, C. F., \& Nogueira, S. (2013). Relações sociais, estereótipos e envelhecimento. Actas de Gerontologia, 1(1), 111.

Andrews, M. (1999). The seductiveness of agelessness. Ageing and Society, 19(3), 301-318.

Baltes, P. B., \& Baltes, M.M. (1990). Successful aging: perspective from the behavioral sciences. Cambridge: Cambridge University Press.

Bauman, Z. (2004). Amor líquido: Sobre a fragilidade dos laços humanos. Rio de Janeiro: Zahar.

Correa, M. R. (2009). Cartografias do envelhecimento na contemporaneidade: velhice e terceira idade. São Paulo: Unesp.

Debert, G. G. (1999). A reinvenção da velhice: sociabilização e processos de reprivatização do envelhecimento. São Paulo: Editora da Universidade de São Paulo.

Debert, G. G. (2002, maio/agosto). A reinvenção da velhice: socialização e processos de reprivatização do envelhecimento. São Paulo: Universidade de São Paulo/Fapesp. Pro-Posições, 13(2). Recuperado em 27 novembro, 2013, de http: //www. proposicoes.fe. unicamp. br/ proposicoes/textos/38-resenhas-goncalvesm. pdf

Domingues, I. (1999). O grau zero do conhecimento: o problema da fundamentação das ciências humanas. São Paulo: Loyola.

Ferreira, V. R. T. (2005). Psicoterapia e pós-modernidade: problemas da subjetividade e da psicologia clínica no contemporâneo. Revista de Psicologia da UNC, 2(2), 128-133.

Goldfarb, D. C. (2004). Do tempo da memória ao esquecimento da história: um estudo psicanalítico das demências. Tese de doutorado, Instituto de Psicologia, Universidade de São Paulo, São Paulo, SP, Brasil.

Goldfarb, D. C. (2006). Velhices fragilizadas: espaços e ações preventivas. In Velhices: reflexões contemporâneas. Edição comemorativa dos 60 anos SESC e PUCSP. Org. SESC-PUCSP (pp. 73-85). São Paulo: SESC-PUC.

Herédia, V. B. M., Corteletti, I. A., \& Casara, M. B. (2007). O processo de envelhecimento e a institucionalização do idoso. In V. B. M. Herédia, A. A. Ferla, \& D. R. S. Lorenzi (Orgs.), Envelhecimento, saúde e políticas públicas (pp. 23-31). Caxias do Sul, RS: Educs. 
Instituto Brasileiro de Geografia e Estatística (IBGE). (2009). Síntese de indicadores sociais. Rio de Janeiro. Recuperado em 26 maio, 2013, http://www.ibge.gov.br/home/estatistica/população/condicaode vida/indicadoresminimos/sinteseindicsociais2009/indic_sociais2 009. pdf

José, J., \& Teixeira, A. R. (2014, janeiro/março). Envelhecimento Ativo: contributo para uma discussão crítica. Análise Social, 210(49). ISSN ONLINE 2182-2999.

Lima, T. C. S., \& Mioto, R. C. T. (2007). Procedimentos metodológicos na construção do conhecimento científico: a pesquisa bibliográfica. Revista Katálysis, 10(n. esp.), 37-45.

Lipovetsky, G. (2009). O império do efêmero: a moda e seu destino nas sociedades modernas. São Paulo: Companhia das letras.

Luz, M. M. C., \& Amatuzzi, M. M. (2008). Vivências de felicidade de pessoas idosas. Estudos de Psicologia, 25(2), 303-307.

Minayo, M. C. S. (2006). Visão antropológica do envelhecimento. In: Vários colaboradores (Orgs.), Velhices: reflexões contemporâneas (vol. 1, pp. 47-60). São Paulo: SESC: PUC.

Moreira, J. O. (2012). Mudanças na percepção sobre o processo de envelhecimento: reflexões preliminares. Psicologia: Teoria e Pesquisa, 28(4), 451-456.

Moreira, V., \& Nogueira, F. N. N. (2008). Do indesejável ao inevitável: a experiência vivida do estigma de envelhecer na contemporaneidade. Psicologia USP, 19(1), 59-79.

Mori, M. M. (2006). Aposentadoria e trabalho: investigação sobre a (re)inserção do idoso no mercado de trabalho. Dissertação de Mestrado em Gerontologia, Pontifícia Universidade Católica de São Paulo, São Paulo, SP, Brasil.

Neri, A. L. (1993). Qualidade de vida e idade madura. Campinas, SP: Papirus.

Neri, A. L. (2004). Velhice bem-sucedida: aspectos afetivos e cognitivos. Psico-USF, 9(1), 109-110.

Neri, A. L. (2006). Atitudes em relação à velhice: questões científicas e políticas. In E. V. Freitas, L. Py, F. A. X. Cançado, J. Doll, \& M. L. Gorzoni (Eds.), Tratado de Geriatria e Gerontologia (2a ed. rev. e ampl., pp. 1316-1323). Rio de Janeiro: Guanabara Koogan.

Neri, A. L., \& Freire, S. A. (2000). Qual a idade da velhice? In A. L. Neri, \& S. A. Freire, (Orgs.), E por falar em boa velhice (pp. 719). Campinas: Papirus.

Peres, M. A. de C. (2007). Velhice, trabalho e cidadania: as políticas da terceira idade e a resistência dos trabalhadores idosos à exclusão social. Tese de Doutorado em Educação, Faculdade de Educação da USP, São Paulo, SP, Brasil. 
Pitanga, D. A. (2006). Velhice na cultura contemporânea. Dissertação de Mestrado, Centro de Teologia e Ciências Humanas, Universidade Católica de Pernambuco, Recife, PE, Brasil.

Rodrigues, P. K.A. (2008). O discurso da publicidade brasileira: construção e desconstrução de estereótipos da velhice. Dissertação de Mestrado, Pontifícia Universidade Católica de São Paulo, São Paulo, SP, Brasil.

Rowe, J. W., \& Kahn, R. (1998). Successful aging. New York: Pantheon Books.

Sad, I. (2001). Revisão de vida, autoconhecimento e autoaceitação: tarefas da maturidade. In A. L. Neri (Org.). Desenvolvimento e envelhecimento: perspectivas biológicas, psicológicas e sociológicas (pp. 53-69). São Paulo: Papirus.

Salvador, A. D. (1986). Métodos e técnicas de pesquisa bibliográfica. Porto Alegre: Sulina.

Schneider, R. H., \& Irigaray, T. Q. (2008). O envelhecimento na atualidade: aspectos cronológicos, biológicos, psicológicos e sociais. Estudos de Psicologia, 25(4), 585-593.

Silva, H. S., Lima, A. M. M., \& Galhardoni, R. (2010). Envelhecimento bem-sucedido e vulnerabilidade em saúde: aproximações e perspectivas. Interface - Comunicação, Saúde e Educação, 14(35), 867-877.

Tolotti, M. (2005). Passageiros do Outono: Reflexões sobre a velhice. Caxias do Sul: Maneco Livr. \& Ed.

World Health Organization (WHO). (2002). Active Ageing: A Policy Framework. Geneva.

World Health Organization (WHO). (2005). Envelhecimento ativo: uma política de saúde. Brasília: Organização Pan-Americana da Saúde. Recuperado em 16 fevereiro, 2013, de http://www. prosaude.org/ublicações/diversos/envelhecimento_ ativo.pdf

\section{Endereço para correspondência}

Selena Mesquita de Oliveira Teixeira

Universidade de Fortaleza

Programa de Pós Graduação em Psicologia

Av. Washington Soares 1321, Edson Queiroz, CEP 60811-905, Fortaleza - CE, Brasil Endereço eletrônico: selenateixeira@hotmail.com

\section{Fernanda Xavier Santiago Marinho}

Universidade de Fortaleza

Programa de Pós Graduação em Psicologia

Av. Washington Soares 1321, Edson Queiroz, CEP 60811-905, Fortaleza - CE, Brasil Endereço eletrônico: fernandaxsmarinho@gmail.com

\section{Andressa Maria Correia Vasconcelos}

Universidade de Fortaleza

Programa de Pós Graduação em Psicologia

Av. Washington Soares 1321, Edson Queiroz, CEP 60811-905, Fortaleza - CE, Brasil

Endereço eletrônico: andressa.maria@hotmail.com 


\section{J osé Clerton de Oliveira Martins}

Universidade de Fortaleza

Programa de Pós Graduação em Psicologia

Av. Washington Soares 1321, Edson Queiroz, CEP 60811-905, Fortaleza - CE, Brasil Endereço eletrônico: jclertonmartins@gmail.com

Recebido em: 04/02/2015

Reformulado em: 15/03/2016

Aceito para publicação em: 31/03/2016

\section{Notas}

* Doutoranda e Mestra pelo Programa de Pós Graduação em Psicologia da Universidade de Fortaleza (UNIFOR), Bolsista da Fundação Cearense de Apoio ao Desenvolvimento Científico e Tecnológico (FUNCAP). Membro do Laboratório de Estudos sobre Processos de Exclusão Social (LEPES). Professora da Faculdade Integral Diferencial (FACID Devry).

** Mestra em Psicologia pelo Programa de Pós-Graduação em Psicologia da Universidade de Fortaleza (UNIFOR). Especialista em Saúde do Idoso (UNICHRISTUS). Membro do Laboratório de Estudos sobre Ócio, Trabalho e Tempo livre (OTIUM). Professora da Faculdade Ateneu (FATE).

*** Mestra em Psicologia pela Universidade de Fortaleza (UNIFOR). Professora do Curso de Psicologia da Faculdade Nordeste (FANOR DeVry), Fortaleza, Ceará, Brasil.

**** Doutor em Psicologia (2001) pela Universitat de Barcelona (Catalunya/España). Pós-doutorado (CAPES 2005-2006) realizado na Universidad de Deusto (Pais Basco/España). Professor Visitante/Catedrático do Programa de Doutorado em Estudos Culturais) das Universidades do Minho e de Aveiro/Portugal. Atualmente está vinculado ao Programa de Pós-Graduação em Psicologia da Universidade de Fortaleza (UNIFOR).

Agradecimentos à Fundação Cearense de Apoio ao Desenvolvimento Científico e Tecnológico pelo financiamento desta pesquisa. 